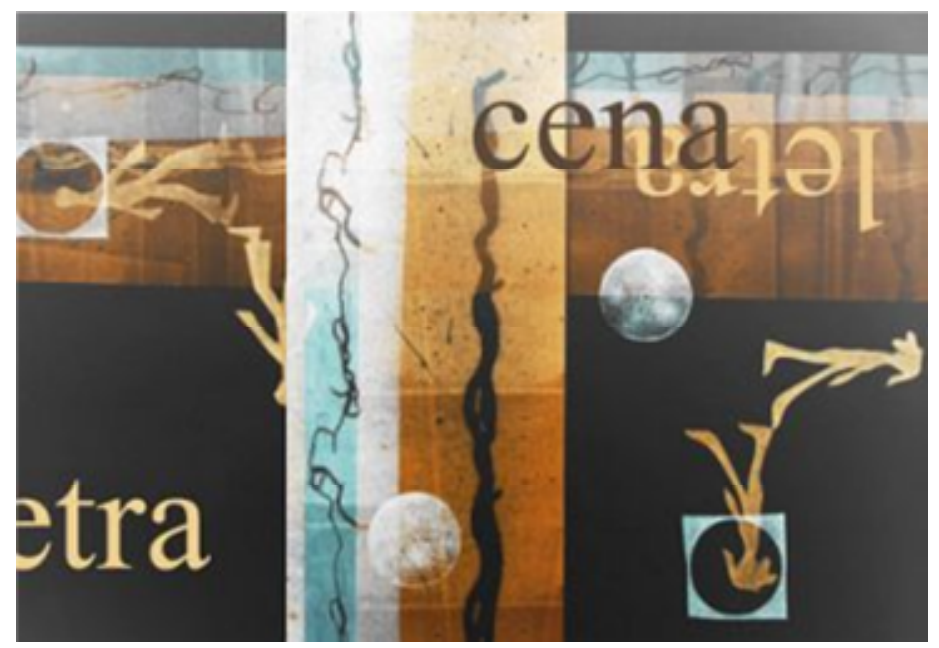

Ilustração Mario Vinícius Júnior da Silva

\title{
Lendo o teatro: letra e cena(1)
}

\section{Antonio Barreto Hildebrando}

Antonio Hildebrando é ator, dramaturgo e diretor de teatro. Mestre em Letras e Doutor em Literatura Comparada. Professor Adjunto do Curso de Graduação em Teatro e do Mestrado em Artes da Escola de Belas Artes/UFMG. Desenvolve pesquisas relacionadas a Dramaturgia, Teatro Épico e Formação de Atores.

\section{Resumo}

Este artigo aborda algumas questões sobre a relação entre o "texto escrito para o teatro" e a cena. Envolve, ainda, algumas observações sobre a escrita e a leitura desse tipo de texto e sobre sua encenação.

Palavras-chave: teatro, dramaturgia, texto dramático, encenação. 
As definições - e o pensar a respeito de definições - são coisas valiosas e essenciais, porém jamais devem ser transformadas em absolutos; quando o são transformam-se em obstáculos ao desenvolvimento orgânico de novas formas, à experimentação e à invenção. É precisamente porque uma atividade como o drama tem delimitações fluidas que ela pode renovar-se continuamente a partir de fontes que, até aquele momento, haviam sido consideradas para além de seus limites.

Desde que a necessidade humana de expressão - e de explicação do mundo - trouxe à luz realizações chamadas artísticas, a busca pelo entendimento dos processos criativos tende a se degenerar na tentativa de aprisionar tais realizações em moldes rígidos, impondo-lhes regras, criando limites, fornecendo receitas de excelência estética. Se, por um lado, tais receitas podem, mais do que servir de norte aos criadores, representar um entrave à criação, por outro lado, funcionam como um desafio para artistas rebeldes, dando impulso a novas criações.

Assim se dá com o drama, aqui considerado apenas, seguindo a classificação de Emil Staiger, como "uma composição para o palco" (2). Trata-se de um texto literário (3) que, em sua gênese, pressupõe uma posterior encenação e, embora possa ser lido e analisado independentemente de sua atualização cênica, somente nesta ultrapassa os limites da literatura para se tornar um dos elementos constitutivos do teatro. Assim, em primeiro lugar, coloca-se o fato de o dramaturgo, ao escrever um texto para o teatro, ter em mente uma posterior encenação, determinando os recursos que irá utilizar. Como afirma Anne Ubersfeld,

\begin{abstract}
é difícil (salvo raríssimos casos) compreender a produção do texto de teatro sem levar em conta o fato capital de que o texto de teatro não poderia ser escrito sem a presença de uma teatralidade anterior; não se escreve para o teatro sem saber nada de teatro. Escreve-se para, com, ou contra um código teatral preexistente. De um certo modo a "representação", no sentido mais amplo da palavra, preexiste ao texto; o autor de teatro, quando não está ele mesmo envolvido na produção teatral, não escreve, apesar disso, sem a perspectiva imediata do objeto-teatro: a forma da cena, o estilo dos atores, sua dicção, o tipo de figurino, o tipo de história que conta o teatro que ele conhece, e outros tantos elementos que inserem o autor em um certo modo de escrita (4).
\end{abstract}

Complementando a esclarecedora citação, é preciso dizer que mesmo questões práticas (tipo de público a que será apresentado, duração prevista para o espetáculo e até, no caso do autor/encenador, a verba disponível para a montagem) costumam assumir importância determinante nas escolhas do autor que pretende ver sua obra encenada. 
Entre os recursos de "um certo modo de escrita" à disposição do autor dramático, encontram-se as rubricas. O que nos faz reconhecer, de imediato, o texto para o teatro é a presença das réplicas, as falas dos personagens representadas pelos diálogos e - no caso do teatro épico - também pelas narrações ou letras das canções. É necessária, entretanto, a percepção de que o texto para o teatro comporta dois tipos de enunciados: 0 manifestado pelas falas e 0 composto nas rubricas ou indicações cênicas, também conhecidas por "didascálias". A crítica literária tende a desconsiderar as rubricas por julgá-las somente indicações para uma posterior transposição do texto à cena (o que elas também são!), pensando-as, às vezes, como estorvo "estético" por quebrarem a continuidade das falas, vistas, então, como o único elemento pertinente para a análise literária dos dramas.

As rubricas são fundamentais para se chegar à especificidade do drama, ou seja, elas surgem da consciência do autor de estar escrevendo uma obra que tem como objetivo último se corporificar na encenação. Assim, as rubricas são transpostas para outro código, incorporando e ultrapassando o lingüístico. A partir dessa consciência, o enunciador do texto dramático funciona como o primeiro encenador, enviando ao destinatário, no caso, o leitor (no papel de encenador virtual), informações que situem as falas dos personagens no tempo e no espaço, bem como fornecendo "dicas" sobre suas motivações e intenções secretas não expressas nas falas. Às vezes, o autor transcende a função e a redação técnica desse texto que é "no fenômeno teatral, um território privilegiado de interseção entre os planos literário e cênico" (5). Apenas para pinçar um exemplo, trago a rubrica na qual Bernardo Santareno - em $O$ judeu descreve Leonor, mulher de António José: "Vinte e dois anos; dois olhos negros e imensos, que toda a resumem; asas de vôo alto e livre, em contradição, por vezes deseperada, com os membros de fundas e terrenas raízes" (6). Nesta e em várias outras rubricas do texto do dramaturgo português seria difícil pensar em mera descrição técnica. O "desprezo" pelas rubricas aponta para a indefinição que cerca o estudo de dois objetos distintos: drama e encenação. Vítor Manuel de Aguiar e Silva, comentando a questão, afirma que "no drama, as figuras se desenham como gestos... o dramaturgo não domina as suas personagens e para as revelar, só pode recorrer à voz, ao gesto, ao silêncio e à encenação"(7). Tal afirmação é extremamente pertinente em relação à encenação mas, no drama escrito, o autor pode recorrer a algo mais: às rubricas.

Para a arte do espetáculo, entretanto, a letra não tem que ser o ponto de partida, que pode deslocar-se, por exemplo, apenas para as sensações e sentimentos experimentados pelos atores em seus laboratórios, surgindo daí a possibilidade de, posteriomente, aparecer um roteiro escrito - espécie de 
síntese de uma experiência coletiva - que seria, então, um "texto do teatro". Resultado do processo de encenação. Ponto de chegada, não de partida.

Fixado na letra, o texto, seja "para o" ou "do" teatro, é sempre, em certa medida, provisório. Aguarda apenas que uma nova encenação, ao mesmo tempo releitura e reescrita cênica, lhe imprima novas variantes, novos sentidos, mesmo sem modificar nenhuma palavra. A cada vez que leio o Auto da alma de Gil Vicente, pensando em uma possível montagem (apenas para encenar meu pensamento), vejo a alma a despir o "vestido e jóias que lh'o imigo deu" (8) ao mesmo tempo em que os representantes da Igreja guardam sofregamente tais objetos em um grande baú. Assim, com a inserção de um elemento cênico não sugerido pelo autor em suas rubricas, as intenções da Igreja de purificar e "aliviar" o peso da alma não mais seriam as que Gil Vicente procurou mostrar no Auto. Embora semelhante alteração pudesse ser justificada pela crítica do autor à Igreja, levada a termo em outros autos, o fato é que a encenação põe em questão a própria noção de autoria. Como observa Patrice Pavis, é sempre necessário perguntar:

A que ideologização são submetidos o texto dramático e a representação? O texto, seja ele dramático ou espetacular - só se compreeende em sua intertextualidade, principalmente em relação às formações discursivas e ideológicas de uma época ou de um corpus de textos. Trata-se de imaginar a relação do texto dramático e espetacular com o contexto social, isto é, com outros textos e discursos mantidos sobre o real por uma sociedade. Sendo esta relação das mais frágeis e variáveis, o mesmo texto dramático produz sem dificuldade uma infinidade de leituras e, portanto, de encenações imprevisíveis a partir somente do texto (9).

Para se transformar em voz é que a letra pede, exige uma estrutura, uma forma (não "fôrma"), uma construção própria. A prerrogativa do texto de poder vir a ser o ponto de partida de um espetáculo, de participar de uma encenação, lhe permite, paradoxalmente, freqüentar o espaço da literatura, justamente porque não se satisfaz em ser, por exemplo, um romance defeituoso, um romance sem descrições e sem - ou quase sem narração, mas se transforma em uma obra com um estatuto próprio, o que lhe permite ser, ao mesmo tempo, completo e lacunar, estável e provisório, e por isso fascinante, solicitando ao leitor uma maneira especial de o ler.

A leitura do drama pode ser extremamente prazerosa, mas é preciso, ao abordá-lo, uma postura diferente da que temos em relação à poesia ou à narrativa. O que é normalmente apontado como sendo o problema na leitura do texto para o teatro, ou seja, as lacunas a serem preenchidas pela encenação (10), podese transformar em sua maior qualidade. Sua leitura é atraente justamente porque o leitor pode preencher as lacunas com sua imaginação e "completar" o sentido do que está na letra com 
sua própria interpretação, tornando-se, com isso, um encenador virtual com total liberdade para corroborar ou subverter a mensagem do autor.

Para que o leitor se torne um encenador virtual, ele necessita da "perspectiva imediata do objeto-teatro" (11). A sua imaginação precisa agir dentro de um determinado espaço cênico (palco italiano, palco elizabetano, arena, rua etc.) e suas convenções. Como observa Jean-Pierre Ryngaert,

Ler o texto de teatro é uma operação que se basta a si mesma, fora de qualquer representação efetiva, estando entendido que ela não se realiza independentemente da construção de um palco imaginário e da ativação de processos mentais como em qualquer prática de leitura, mas aqui ordenados num movimento que apreende o texto "a caminho do palco" (12).

Se penso, mantendo o exemplo, na "alma" a caminho da salvação e "do palco", preciso construir um cenário, vesti-la com um determinado figurino, iluminá-la e corporificá-la na figura de um ator, seja ele um daqueles que posso encontrar no meu arquivo teatral-televisivo-cinematográfico, ou um vizinho alçado à condição de ator, ou mesmo um ser imaginário, mas com corpo e voz tão definidos que me permitam vê-lo e ouvi-lo. Eu, leitor, preciso dominar o mecanismo que me faz sair da frente do livro para estar, virtualmente, na posição de espectador que vê no palco a letra transformada em voz.

Na maior parte da história do teatro ocidental, a literatura dramática foi o elemento privilegiado na abordagem do fenômeno teatral. Já Aristóteles, em sua Poética, abrira caminho para a idéia de que o valor do espetáculo se apequenava frente ao texto literário, ao afirmar que "O espetáculo, embora fascinante, é o menos artístico e mais alheio à poética; dum lado, o efeito da tragédia subsiste ainda sem representação nem atores; doutro, na encenação, tem mais importância a arte do contra-regra do que a dos poetas" (13).

Ampliando o rol de interpretações de Aristóteles, posso dizer, de forma bastante livre, que o filósofo não pregava a subordinação do espetáculo ao texto, mas apenas lhe dava estatuto e poética próprios, segundo ele do domínio do contraregra. Interpretando dessa maneira, penso que Aristóteles apenas preconizou a existência de duas artes: a do texto dramático e a do espetáculo.

Se atualizo a afirmação de Aristóteles e penso no papel do encenador moderno, vejo que este, ultrapassando a função de organizar cenicamente o espetáculo de acordo com a tradição, assegurando-lhe unidade e criando uma "bela moldura" possivelmente a função do contra-regra de Aristóteles assumiu a posição de leitor privilegiado, aquele encenador 
virtual que é uma espécie de co-autor (como no caso da hipotética montagem do Auto da alma). Ele não só transpõe para - palco a encenação proposta pelo autor na obra impressa, mas a interpreta e, às vezes, modifica-a, influindo decisivamente no sentido, na mensagem a ser decodificada pelo público. Notese, entretanto, que, como alerta Jean Jacques Roubine,

\begin{abstract}
até uma época recente, digamos até o fim da década de 1950, a noção de polissemia não era praticamente admitida. Supunha-se que um texto de teatro veiculava um único sentido, do qual o dramaturgo detinha as chaves. Assim sendo, cabia ao encenador e aos seus intérpretes a tarefa de mediatizar esse sentido, fazer com que ele fosse apreendido (compreendido, sentido...) da melhor maneira possível pelo espectador (14).
\end{abstract}

Aceita a polissemia do texto para o teatro e admitindo-se, assim, que as mesmas chaves possam abrir diferentes portas, não há, pensando na encenação, exagero na posição de Anne Ubersfeld que, retomando Brecht, afirma que ele: "nos ensina que não se pode distinguir um autor dramático, criador único do seu texto, do encenador, do homem de teatro que o encena. Um e outro são os sujeitos plurais de uma só e mesma produção" (15) .*

Desde o contra-regra de Aristóteles - ou, mais precisamente, o didaskalus do teatro grego -, passando pelo meneur de jeur medieva, 1 os arquitetos e cenógrafos renascentistas e barrocos, os grandes atores do século XVIII e início do XIX, sempre houve alguém que tinha a função de organizar o espetáculo ou instruir os atores. Mas, para o surgimento de uma arte autônoma como a concebemos hoje, foi preciso aguardar até o naturalismo e o aparecimento de encenadores como, dentre outros, André Antoine (1858-1943), considerado, pela maioria dos estudiosos, como o primeiro encenador moderno e Constantin Stanislavski (1863-1938), o mestre russo que revolucionou a arte da atuação. Nas palavras de Bernard Dort,

O advento do encenador provoca no exercício do teatro o aparecimento de uma nova dimensão: a reflexão sobre a obra. Entre esta obra e o público, entre um texto "eterno" e um público que se modifica, submetido a condições históricas e sociais determinadas, existe agora uma mediação (16).

O surgimento da figura do encenador/mediador possibilitou o início do processo de libertação - que chegará ao auge com a obra de Antonin Artaud (1896-1948) - do teatro do jugo da literatura, garantindo-lhe o estatuto de arte autônoma e não de simples veículo da literatura dramática. Com Bertolt Brecht e seu trabalho frente ao Berliner Ensemble - grupo com o qual ele pôde testar, aprofundar ou abandonar idéias, criando um espaço calcado na inter-relação entre teoria e prática - se encontra um dos melhores exemplos da via de mão dupla estabelecida entre o texto e a encenação. 
Retornando a Aristóteles, vê-se que nem tudo que a ele se atribui encontra-se em sua obra. Exemplo clássico disso é a questão das três unidades. Se em relação às unidades de tempo e ação muito se pode discutir, é certo que Aristóteles não faz nenhuma menção à unidade de lugar. É somente com a redescoberta da poética no século XVI que a regra das unidades passa a ser entronizada como condição essencial para a confeç̧ão de um drama.

De qualquer maneira, criação de Aristóteles ou resultado das inúmeras interpretações sofridas pela Poética, é possível se chegar a um elenco mais ou menos estável de características pertencentes a um tipo de texto para o teatro, o drama, ao qual Brecht acrescentou o adjetivo aristotélico (17), contrapondo-o a um outro tipo, logicamente denominado nãoaristotélico. Entre as principais características do primeiro tipo de drama aqui apontado, apresenta-se, além da observância, em maior ou menor grau, da regra das três unidades, a causalidade da ação. Por ela, cada cena é determinada pela que a antecede e determina a seguinte, garantindo ao drama/espetáculo a existência de uma seqüência caracterizada pela presença bem determinada de início, meio e fim, gerando um aumento gradativo de tensão, como já preconizara Aristóteles.

Outro elemento fundamental para a caracterização do drama chamado aristotélico, mas que não tem relação com a Poética, é a primazia do diálogo estabelecida na Renascença - período que Peter szondi classifica, em oposição à visão de mundo medieval, como de relações "entre os homens" ou "entre sujeitos", que resolvi traduzir como interpessoais:

\footnotetext{
O meio de expressão lingüística deste mundo de relações interpessoais era - diálogo, que se tornou, na Renascença, depois da eliminação do prólogo, do coro e do epílogo, talvez pela primeira vez na história do teatro (ao lado do monólogo que permaneceu episódico, não constituindo efetivamente a forma dramática) no componente exclusivo do tecido dramático. o drama clássico diferencia-se, neste ponto, tanto da tragédia antiga como dos mistérios medievais e, ainda, do Teatro do Mundo do barroco e das peças históricas de Shakespeare. O domínio exclusivo do diálogo, isto é, da troca interpessoal no drama, comprova o fato de que só se conhece o que brilha nesta esfera (18)*.
}

Tendo em vista o "domínio exclusivo" do diálogo, Szondi classifica o drama - agora significando um tipo específico de texto para o teatro - como "absoluto", ou seja, nada deve surgir no drama que não tenha origem nele mesmo, na relação interpessoal, no caso, entre os personagens, impossibilitando, dessa forma, qualquer tipo de comentário ou observação do que ele denomina o "eu-épico". Além de absoluto, de acordo com o teórico, o drama é "primário", o que para ele significa estar desvinculado da história, de fatores externos ao presente da ação dramática, tornando-se, então, um universo fechado em si 
mesmo. É contra esse tipo de drama "desistoricizado", que transforma o espectador em um elemento passivo, que Bertolt Brecht elabora sua teoria, bem como seus "dramas épicos".

Em alguns dos períodos da história do teatro ocidental referidos por Peter szondi, tais características ditas aristotélicas poderiam, é claro, estar presentes, mas não assumiam nenhum caráter normativo, como ocorreu a partir do século XVI, principalmente na França. Como afirma Anatol Rosenfeld:

\begin{abstract}
Proclamando-se herdeira exclusiva de Aristóteles, fiada em regras absolutas e universais, independentes de situações históricogeográficas, a dramaturgia clássica se afigurava aos olhos do mundo como um modelo insuperável. Para destruir a sua função de modelo era necessário mostrar que a teoria e a obra dos franceses de modo algum correspondiam nem ao espírito nem à letra do pensamento aristotélico (19).
\end{abstract}

Assim, para quebrar o modelo erigido pelos discípulos de Aristóteles - nem sempre fiéis ao mestre - retornava-se à Poética. O alemão Gotthold Ephrain Lessing, em sua Hamburgische Dramaturgie (Dramaturgia de Hamburgo) (1767), afirmava que a catarse era o objetivo último da tragédia $e$, para alcançá-la, não importava que se violassem as regras, como havia feito Shakespeare - que, para Lessing, era o mais bem acabado exemplo do "gênio". As idéias de Lessing - que, na realidade, queria trazer para o palco personagens com os quais - público burguês se pudesse identificar, expulsando da cena os reis e as rainhas dos dramas franceses (20) - influenciaram decisivamente a dramaturgia dos pré-românticos e românticos alemães que, por sua vez, atravessaram a fronteira, influenciando o teatro romântico francês.

"Vencido" o modelo clássico, em um teatro liberado das amarras das regras e da pureza dos gêneros, os personagens já podiam travar seus duelos em prosa ou verso, mas o diálogo, a relação interpessoal, via de regra, continuou dominando até que outro alemão protestou contra a dramaturgia vigente, excludente de temas que extrapolavam a relação interpessoal. O dramaturgo afirmava que "o petróleo, a inflação, a guerra, as lutas sociais, a família, o trigo, o comércio do gado de abate se tornaram assuntos de representação teatral" (21).*

Neste salto olímpico de Lessing a Brecht, passei, propositadamente, sobre um sem-número de tendências, teóricos e artistas fundamentais para a história da dramaturgia e do teatro ocidental, apenas porque o primeiro reivindicou a catarse como objetivo final do drama e, para alcançá-la, propunha aos dramaturgos a transgressão de qualquer regra estabelecida, e o último fez da mesma catarse a ovelha negra da dramaturgia aristotélica, erigindo uma vasta obra orientada 
no sentido de encontrar meios de evitá-la. Para abrir um parêntese, exigido quando se fala em catarse, é sempre bom relembrar a advertência de Esslin, (22), epígrafe que abre este artigo.

Sendo uma arte que é duas - literatura e espetáculo - o teatro se tem mostrado como uma das mais complexas manifestações artísticas, estimulado a ânsia dos estudiosos por definições. A Poética de Aristóteles é, como já dito, o passo inicial para a análise do fenômeno teatral, porém, como afirma Roberto de Oliveira Brandão na introdução à Poética clássica, editada pela Cultrix em 1981,

Aquilo que em Aristóteles correspondia certamente a um trabalho de reflexão a partir de uma realidade histórico-artístico-cultural pode dar lugar, e isso de fato aconteceu, ou a um critério estratificado que se aplicava às formas artísticas, ou, no melhor dos casos, a um estímulo para reproduzir os atos de observação e de reflexão capazes de encontrar no novo a dinâmica interna que permanece (23).

A afirmação acima bem pode ser aplicada à obra de Brecht, que alguns tentam estratificar e, de resto, a qualquer obra. Felizmente "o melhor caso", conforme Roberto de Oliveira Brandão, também se aplica em relação ao dramaturgo, teórico e encenador alemão. Infelizmente, porém, grande parte da crítica, principalmente a que privilegia a letra, utiliza esse critério estratificado, espécie de camisa de força a ser vestida em todo e qualquer texto para o teatro. É claro que o drama levado à cena, quando retorna às prateleiras da biblioteca, mantém sua independência como obra literária. Mesmo integrada ao espetáculo, a letra - afora as rubricas, caso não entrem em cena via cartazes e/ou projeções ou sejam ditas pelos próprios atores, voz em off etc. - não se dissolve ao calor dos refletores. O espectador médio percebe o texto ou quaisquer outros elementos cênicos - iluminação, figurino, cenário - como um elemento à parte, embora não possa determinar o grau de fidelidade do encenador à letra impressa. Não é raro, à saída de um espetáculo teatral, se ouvirem comentários elogiosos em relação ao texto ou à iluminação, por exemplo, e depreciativos em relação ao espetáculo como um todo e vice-versa.

Para tornar menos marcante o descompasso entre letra e cena, surge, na esteira de Antoine e do teatro naturalista, um tipo de encenador-ilusionista, uma espécie de maestro, que tentará criar um todo indissociável e fazer com que o visitante incauto se esqueça de estar no teatro e seja, "abdicando" da razão, levado à catarse total, à purgação das paixões. Mas há também maestros rebeldes, que optam pela dissonância e, para evitar tal catarse, forçam a batuta para mostrar ao 
espectador, realçando cada elemento, que tudo o que ele vê é apenas teatro.

Os excessos quanto à importância do texto ou da encenação, ora privilegiando aquele, ora esta, são uma constante na história do teatro. Assiste-se, no momento, a algumas reações à figura do encenador, tornada tão importante que, de certa forma, quase eclipsou a do autor. Pode-se mesmo questionar se a especificidade de cada obra escrita não tem sido esquecida e, assim, textos das mais variadas correntes passam a ser determinados pelo estilo do encenador. Fala-se, hoje, muito mais na Antígona deste ou daquele encenador do que "na de Sófocles". Eurípedes, Shakeaspeare, Racine ou Brecht são uniformizados pelo estilo do encenador. Por outro lado, as condições de produção também limitam a experimentação e a variedade de propostas de montagem. Brecht posicionou-se em relação a esse ponto no artigo "Um teatro de feição literária" (24), ao afirmar que

Verificamos hoje em dia um primado absoluto do teatro sobre a literatura dramática. Um primado da engrenagem(25) teatral, isto é, dos meios de produção. A engrenagem resiste a qualquer transformação que tenha em vista outros fins que não os seus. Ao contactar com o drama, é ela que logra modificá-lo, assimilando-o - exceto os casos em que o drama a si próprio se aniquila (26).

Certamente Brecht não está, com essa afirmação, reivindicando a primazia do texto literário, mas alertando o produtor para que não caia na esparrela de crer, inocentemente, estar controlando uma engrenagem que, na realidade, o controla; assim, advoga em causa própria, ou seja, a favor do teatro épico, que ultrapassa a função determinada pela engrenagem do teatro burguês. Evitar o susto de ver seus textos, escritos para o teatro épico, montados sem serem levadas em conta as técnicas, os pressupostos teóricos (e ideológicos!) e o estilo de atuação de tal teatro tecem o pano de fundo do artigo do qual retirei o fragmento acima citado (27) .

\section{Abstract}

This article discusses the relationship between the "text written to the theater" and the scene properly. It involves some special details related to the art of the theater such as play writing, text reading and scene directing.

Key-words: theatre, play writing, play, mise-em-scène. 


\section{Notas}

(1) Parte deste artigo foi publicado em: HILDEBRANDo, Antonio. A letra e a cena: encenação do texto não-dramático. In: HILDEBRANDo, Antonio; NASCIMENTO, Lyslei; ROJO, Sara. O corpo em performance, Belo Horizonte: NELAP, FALE/UFMG, 2003. p. 17-29.

(2) STAIGER, 1975, p. 14

(3) De acordo com Jiri Veltruski: "O drama é uma obra de literatura por direito próprio; não requer mais do que uma simples leitura para penetrar na consciência do público. Ao mesmo tempo, é um texto que pode, e na maioria das vezes pretende, ser usado como componente verbal da representação teatral. Mas algumas formas de teatro preferem ao drama textos líricos ou narrativos; o teatro entra em relação com a literatura como um todo e não apenas com o gênero dramático" (VELTRUSKI, 1978. p.164).

(4) UBERSFELD, 1981, p.14. As traduções, feitas por mim, de trechos de edições estrangeiras virão marcadas (*) por um asterisco.

(5) RAMOS, 1999, p.15. Para o aprofundamento de questões relativas à rubrica, leia-se RAMOS, 1999. Neste livro, o autor demonstra, tendo como base a análise de Cacilda!, de José Celso Martinez Correa, o papel das rubricas como poética cênica de textos produzidos por encenadores e conclui que, nestes casos, o plano das rubricas se torna "uma literatura que toma 0 cênico, ou o espetacular, como tema e como conteúdo" (p.166).

(6) SANTARENO, 1997, p.117.

(7) SILVA, 1973, p. 218.

(8) VICENTE, 1967, p. 159.

(9) PAVIS, 1999, p. 124.

(10) Não que a poesia e a narrativa sejam necessariamente fechadas, sem lacunas, mas não pressupõem, como no caso do drama levado à cena, a existência de outro elemento mediador que não seja o leitor.

(11) cf. p. 02 .

(12) RYNGAERT, 1996, p. 25.

(13) ARISTÓTELES, 1981, p. 26.

(14) ROUBINE, 1998, p. 48

(15) UBERSFELD, 1981, p. 15.

(16) DORT, 1977, p. 68 .

(17) Por exemplo: o Bispo italiano Antonio Sebastiano Minturno, falecido em 1574, escreveu: "Poesia dramática é a imitação, para ser apresentada no teatro, de fatos completos e perfeitos quanto à forma e circunscritos na sua extensão. Sua forma não é a da narração; ela apresenta em cena pessoas diversas, que agem e conversam" (Apud PALLOTINI, 1988, p. 6). Ainda com relação a Minturno, que declarou ser "purificar a alma dos ouvintes, as 
paixões" o objetivo de toda poesia, esclarece Marvin Carlson que se atribui ao Bispo renascentista o "acréscimo de 'emocionar' à tradicional fórmula horaciana 'instruir e deleitar'" (CARLSON, 1997, p. 42). Como se verá, a reação de Brecht ao teatro aristotélico se dirige muito mais ao que foi criado pelos "discípulos" do que à Poética do mestre.

(18) SZONDI, 1963, p. 14/15.

(19) ROSENFELD, 1985, p. 64.

(20) LESSING, 1964.

(21) BRECHT, 1982, p. 82.

(22) ESSLIN, 1978, p. 13-14.

(23) In ARISTÓTELES, 1981, p. 1.

(24) Quando Brecht se refere a um teatro literário, à literalização da cena, ele está propondo a utilização de títulos e explicações, espécie de notas de rodapé, a serem projetados em telões ou afixados no teatro durante o espetáculo.

(25) Na tradução do fragmento, o termo "engrenagem" poderia ser substituído por "aparato", restringindo-se, assim, o sentido mais às condições técnicas para a realização de espetáculos. Optei pela tradução proposta por Fiama Hasse Pais Brandão pelas implicações ideológicas que, na minha opinião, se embutem no termo engrenagem. Brecht nada tinha contra o aparato teatral. A questão era a de quem detinha o controle de tal aparato. Na seqüencia do artigo, ele explica que o aparato desde que seja posto a serviço da construção da sociedade socialista, pode, na sua visão, ser útil para os criadores evitando que eles enveredem por questões "menores".

(26) BRECHT, s/d, p. 36.

(27) O próprio Brecht, entretanto, se sentia bem "à vontade" para realizar sua leitura de textos de outros autores. A sua abordagem dos clássicos da dramaturgia e / ou a reelaboração e ressemantização de influências teatrais e literárias das mais diversas fontes era, pode-se dizer, "antropofágica".

\section{Bibliografia}

ARIStóteles. Poética. In: Aristóteles, Horácio, Longino. A Poética clássica. Trad.

BRECHT, Bertolt. Estudos sobre teatro. Trad. Fiama Hasse Paes Brandão. Lisboa: Portugália, s/d. - Über Experimentelles Theater. Frankfurt: Suhrkamp, 1982.

DORT, Bernard. O teatro e sua realidade. Trad. Fernando Peixoto. São Paulo: Perspectiva, 1977 . 
ESSLIN, Martin. Uma anatomia do drama. Trad. Bárbara Heliodora. Rio de Janeiro: Zahar, 1978 .

LESSING, Gotthold Ephraim. Dramaturgia de Hamburgo. In: Lessing: de teatro e literatura. Trad. Anatol Rosenfeld. São Paulo: Herder, 1964.

PAVIS, Patrice. Dicionário de teatro. Trad. J. Guinsburg e M. Lúcia Pereira.São Paulo: Perspectiva, 1999.

RAMOS, Luiz Fernando. O parto de Godot e outras encenações imaginárias - a rubrica como poética da cena. São Paulo: Hucitec, 1999.

ROSENFELD, Anatol. o teatro épico. São Paulo: Perspectiva, 1985.

ROUBINE, Jean-Jacques. A linguagem da encenação teatral - 1880-1980. Trad. Yan Michalski. Rio de Janeiro: Jorge Zahar Editor, 1998.

RYNGAERT, Jean-Pierre. Introdução à análise do teatro. Trad. Paulo Neves. São Paulo: Martins Fontes, 1996.

SANTARENO, Bernardo. O Judeu. Lisboa: Ática, 1997.

SILVA, Vitor Manuel de Aguiar e. Teoria da literatura. Coimbra: Almedina, 1973.

STAIGER, Emil. Conceitos fundamentais da poética. Trad. Celeste Aída Galeão. Rio de Janeiro: Tempo Brasileiro, 1975.

SzONDI, Peter. Schriften. Frankfurt: Suhrkamp, 1978.

UBERSFELD, Anne. L'école du spectateur; lire le théatre II. Paris: Sociales, 1981 .

VICENTE, Gil. Teatro de Gil Vicente. Lisboa: Portugália, 1967.

VELTRUSKI, Jiri. O texto dramático como componente do teatro. Trad. J. Guinsburg. In: Semiologia do teatro. São Paulo: Perspectiva, 1978. 